University of Nebraska - Lincoln

DigitalCommons@University of Nebraska - Lincoln

$11-2010$

\title{
Relationship of personal, familial, and abuse-specific factors with outcome following childhood sexual abuse
}

C. Thresa Yancey

Georgia Southern University, tyancey@georgiasouthern.edu

David J. Hansen

University of Nebraska-Lincoln, dhansen1@unl.edu

Follow this and additional works at: https://digitalcommons.unl.edu/psychfacpub

Part of the Psychiatry and Psychology Commons

Yancey, C. Thresa and Hansen, David J., "Relationship of personal, familial, and abuse-specific factors with outcome following childhood sexual abuse" (2010). Faculty Publications, Department of Psychology. 550.

https://digitalcommons.unl.edu/psychfacpub/550

This Article is brought to you for free and open access by the Psychology, Department of at DigitalCommons@University of Nebraska - Lincoln. It has been accepted for inclusion in Faculty Publications, Department of Psychology by an authorized administrator of DigitalCommons@University of Nebraska - Lincoln. 


\title{
Relationship of personal, familial, and abuse-specific factors with outcome following childhood sexual abuse
}

\author{
C. Thresa Yancey ${ }^{1}$ and David J. Hansen ${ }^{2}$ \\ 1. Georgia Southern University, Statesboro, GA, USA \\ 2. University of Nebraska-Lincoln, Lincoln, NE, USA \\ Corresponding author - C. T. Yancey, Department of Psychology, Georgia Southern University, \\ P.O. Box 8041, Statesboro, GA 30640-8041, USA; email tyancey@georgiasouthern.edu
}

\begin{abstract}
An examination of the literature on factors related to outcome following child sexual abuse (CSA) revealed many factors that may contribute to symptoms displayed by victims. Factors are divided into three categories: Personal Factors, Familial Factors, and AbuseSpecific Factors. Personal factors are those inherent to the victim, including age, gender, developmental disability, attributions regarding the abuse, and treatment following abuse. Familial factors are defined as those factors associated with other family members. These include parental history of abuse, parental reaction to the disclosure, parental support of the victim, parental mental health, family stress, and treatment following abuse for the parent and other family members. Finally, factors related to the abuse are delineated, including severity of abuse, duration of the abuse, and victim-perpetrator relationship. Directions for future research are discussed.
\end{abstract}

Keywords: child sexual abuse, outcomes

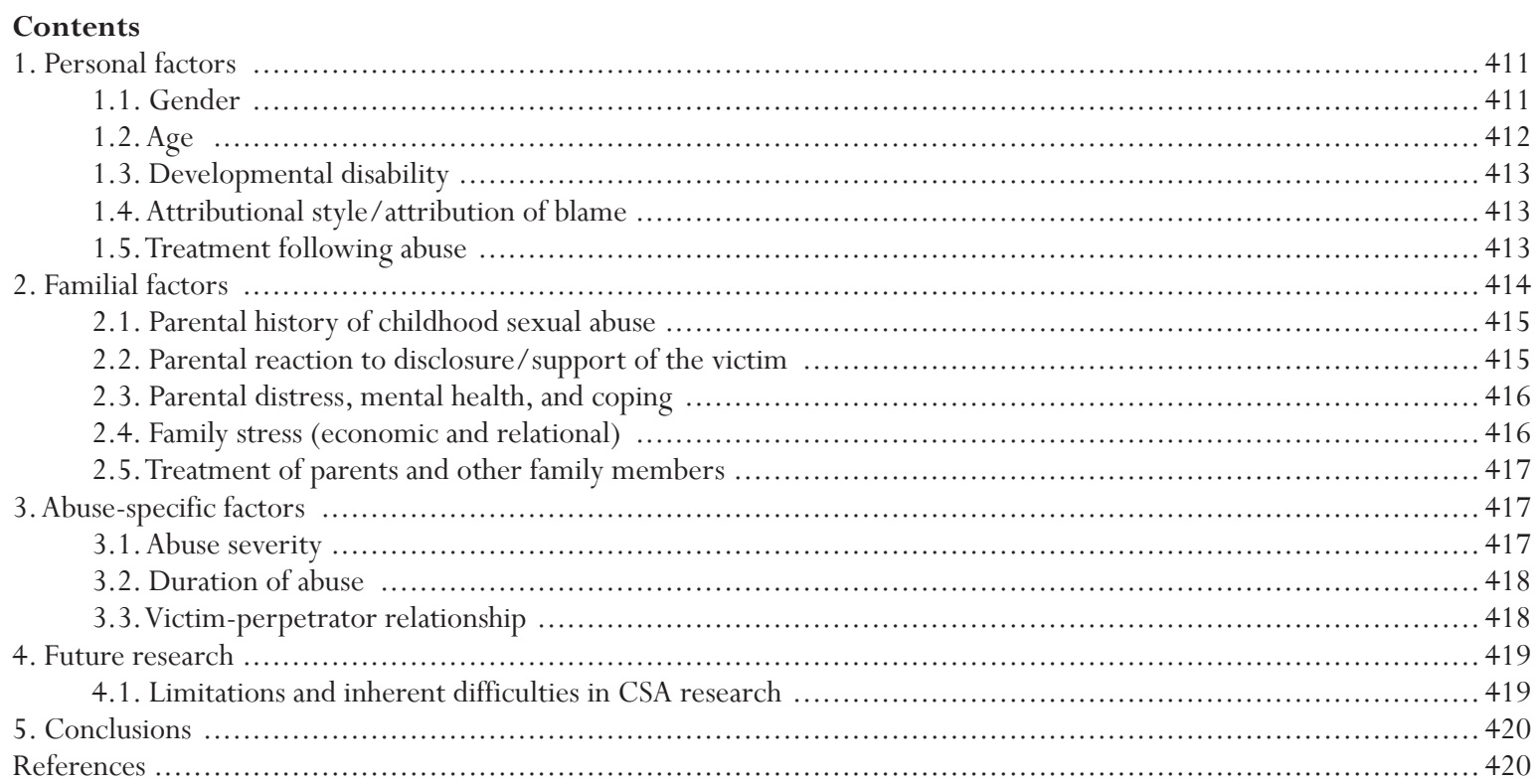

$\mathrm{C}$ hildhood sexual abuse (CSA) has become one of the most widely researched areas in child psychology in recent years. The public has also been made more aware of CSA and possible effects of sexual abuse through efforts from advocacy groups as well as the use of research data in recent political legislation and popular press reports. Recent reports have placed the number of identified CSA victims at 56,460 children during the year 2007 in the United States (U.S. Department of Health and Human Services, Administration on Children, Youth, and Families, 2009). Research estimates of prevalence of CSA range from $27 \%$ to $32 \%$ for females and $13 \%$ to $16 \%$ for males experiencing sexual abuse before adulthood (Berliner \& Elliot, 1996). 
There is little doubt of the seriousness of CSA; however, there are no incontrovertible answers about the outcomes that a child may experience as a result of the abuse. Studies have been unable to specifically illustrate why children portray various outcomes to abuse or to elucidate what factors moderate particular responses by victims.

One important area that affects the difference in the estimated numbers of CSA victims is the way that abuse is defined. Haugaard (2000) states that there are no universal definitions of what CSA consists of in research, treatment, or even among legal definitions. There are difficulties at every turn, including what age range denotes childhood, which acts are considered sexual in nature, and how one determines the intent of the "perpetrator" (Goldman \& Padayachi, 2000; Haugaard, 2000). The lack of a cohesive definition of CSA can make research in the area ambiguous at best and outcomes from research can be difficult to replicate and may not generalize.

Even with all the definitional difficulties, researchers have established patterns of possible outcomes from CSA. Some of these outcomes have been grouped into internalizing, externalizing, and asymptomatic responses (see Kendall-Tackett, Williams, \& Finkelhor, 1993 for a review). Internalizing symptoms are those that include symptoms of depression, anxiety, PTSD, as well as self-harm behaviors and low self-esteem (e.g., Kendall-Tackett et al., 1993; Paolucci, Genuis, \& Violato, 2001). Externalizing outcomes include conduct problems, aggressive behaviors, and sexual behaviors (Paolucci et al., 2001). Most researchers agree that, while there are varied responses to CSA, there are children who show limited or no negative outcomes following CSA (Kendall-Tackett et al., 1993). The meta-analysis completed by Kendall-Tackett et al. (1993) also suggests that victims of CSA tend to return to pre-abuse functioning on many dimensions within 18 months following disclosure of abuse. There are many moderating factors for outcome following CSA that have received limited attention in the literature which may be beneficial in explaining the varied outcomes observed in CSA victims (Kendall- Tackett et al., 1993; Paolucci et al., 2001).

Multifaceted models of traumatization have been proposed by researchers (Conte \& Schuerman, 1987; Finkelhor \& Browne, 1985; Kendall-Tackett et al., 1993) as an explanation for outcomes following CSA. Specifically, Finkelhor and Browne (1985) hypothesize that there are four components to the trauma that a victim experiences following CSA: powerlessness, traumatization related to early sexualization, stigmatization, and betrayal. Conte and Schuerman (1987) postulate based on their research results that both factors of the sexual abuse and other family dysfunction contribute to the trauma that the victim experiences. Further, Conte and Schuerman (1987) hypothesize that the family dynamics will surpass the abuse-related factors in their impact on the victim's outcomes following CSA. Kendall-Tackett et al. (1993) suggest that the pattern of outcomes following CSA is directly related to areas of functioning in which the victim showed prior vulnerability. Beitchman, Zucker, Hood, DaCosta, and Akman (1991) present findings that suggest that children of differing ages display different outcomes and these differences are attributed to developmental differences; however, the meta-analysis completed by Paolucci et al. (2001) did not find significant differences between victims of differing ages, abuse types, or victim-perpetrator relationship.

Prior literature on the outcomes of CSA has noted that there are many potential moderating variables that influence the outcome that a victim may experience (e.g., type of abuse, victim-perpetrator relationship, duration of abuse, age/developmental level of the victim). Unfortunately, there have been few studies that have incorporated these potential moderating variables when examining the effects of CSA (Paolucci et al., 2001). Many researchers include some, but not all moderators that theorists have deemed potentially influential (Paolucci et al., 2001). Prospective moderating variables proposed by theorists and researchers as potentially influential to outcome are presented and discussed. For ease of discussion, these potential moderating variables will be separated into three categories: Personal Factors (e.g., age, developmental level, gender); Familial Factors (e.g., parental history of CSA, family discord, parental reaction to disclosure); and Abuse-Specific Factors (i.e., severity of abuse, duration of abuse, victim-perpetrator relationship). In most prior reviews of literature on outcomes following CSA, not all factors that potentially influence outcome are investigated. In the current review, an attempt is made to include literature on many of the factors that have been shown to influence outcome following CSA. Finally, implications for future research on outcomes following CSA are presented.

\section{Personal factors}

\subsection{Gender}

The relationship between the gender of the victim and the types of outcomes experienced has been a popular area of research within the CSA literature. Earlier research and treatment did not include male victims due to the belief that there was not a large population of male CSA victims (Young, Bergandi, \& Titus, 1994). In general, victims of CSA were thought to be female victims of male perpetrators (Browne \& Finkelhor, 1986; Young et al., 1994). More recent research has included male victims and the outcomes for these male victims are similar to those of female victims (Kendall-Tackett et al., 1993). Male victims, on the whole, are more likely to display aggressive behaviors, conduct problems, and substance abuse (Heath, Bean, \& Feinauer, 1996; Kendall-Tackett et al., 1993; Young et al., 1994). The most common difference discussed between the genders is that male victims tend to display more externalizing outcomes while female victims tend to display more internalizing outcomes (e.g., Kendall- Tackett et al., 1993; Stern, Lynch, Oates, O’Toole, \& Cooney, 1995).

Unfortunately, many studies of outcomes following CSA only examine one gender. Due to this gap in the research of comparing male and female victims, along with studies that do examine both genders and the differences in outcomes based on gender (e.g., Chandy, Blum, \& Resnick, 1996; Young et al., 1994), those that examine outcomes of only one gender were also reviewed.

Young et al. (1994) examined children aged 8 to 11 to determine the current functioning of CSA victims compared to non-victims. In general, the male victims reported higher levels of aggressive behavior than the female victims. The male victims in the study also self-reported lower levels of submissive behaviors and depressive symptoms than the female victims. Of note, it was also reported that the all of the males sampled (both abused and non-abused) reported greater levels of aggression and fewer depressive symptoms than the entire female sample (both abused and non-abused) (Young et al., 1994). The results appear to indicate that male children, not just male victims of CSA, display greater externalizing behaviors than do female children (Young et al., 1994). Regardless of this effect, male victims, when compared to non-victims, displayed greater levels of aggression and a greater prosocial deficit.

In a study comparing the effects of 370 male adolescent victims to 2681 female adolescent victims, Chandy et al. (1996) found that the female victims reported much fewer externalizing symptoms such as difficulties at school, delinquent behaviors, and high-risk sexual interactions. Additionally, male victims reported less depression, suicidal ideation, eating difficulties, and alcohol use. Even though females reported greater alcohol use, male victims reported using marijuana more and tended to drink in larger quantities. For females, emotional attachment to their family, spirituality, believing they were healthy, and having both parents in the home were found to be protective factors for negative outcomes. For males, concern about their well being by 
parents and having a mother with a higher level of education were protective factors.

Some researchers and theorists have suggested that the impact to male victims' sexual development is great. Gilgun (1990) discusses that, based on her extensive life history interviews with 23 adult male victims of CSA, many male victims of male perpetrators display sexual development and gender identity problems, including fears about what the abuse may mean regarding their sexual orientation. Similar hypotheses are presented by Tharinger (1990), who describes the impact on both male and female victims as disruptive to the normal course of sexual development. Male victims are less likely to confide in others and to disclose the abuse, and less likely to receive treatment to cope with feelings following CSA than are female victims (Gilgun, 1990).

When comparing 25 six- to eleven-year old female victims to 25 six-to eleven-year old female children (with no history of abuse) referred to mental health services for other emotional and behavioral problems, Nelson, Moser, Johnson, Graves, and Hart (1999) found that the CSA victims did show elevated internalizing and externalizing symptoms compared to the norms of the assessments used (i.e., Child Behavior Checklist). Compared to the female children referred for other emotional and behavioral problems, the CSA female victims showed lower levels of aggression and somatic complaints. Additionally, the girls referred for other problems showed significantly higher scores on all scales measuring internalizing and externalizing problems than did the CSA victims. It was concluded that the impact of living in a dysfunctional family has a potentially more deleterious effect than CSA alone (Nelson et al., 1999).

The outcomes for 70 young (three to five years old) female victims were found to be similar to female victims in general, and included emotional and behavioral problems, specifically affective and anxious symptoms (Mian, Marton, \& LeBaron, 1996). These young victims were not likely to show externalizing problems, consistent with the results from older and heterogeneous samples of female victims (Mian et al., 1996). Finding similar results, Young et al. (1994) compared 20 abused female children to 40 non-abused male and female children and 20 abused male children. Girls who were abused perceived themselves to have more depressive symptoms than the abused boys, but the caregivers of the children did not report significant differences in depressive symptoms between the male and female victims. There were no differences among caregiver reports for the male and female victims for aggression, social withdrawal, and more inappropriate sexual behaviors. Caregivers of the victims reported greater difficulties with aggression, social withdrawal, and inappropriate sexual behaviors than did the caregivers of non-abused youth. Both the abused children and their caregivers did, however, report that the abused children displayed more depressive symptoms than the non-abused control group.

\subsection{Age}

The age and, thus, the cognitive development of the victim can affect the outcomes that are displayed following CSA. Very young children likely have less understanding of the impact of the abuse, and therefore these victims may not show as many symptoms and negative outcomes following CSA as older children. In turn, older children may have more effective coping strategies which may assist them in returning to pre-abuse functioning following CSA. Many research studies include age as a demographic marker, but seldom use age in analyses as a potential moderator or to examine differences among victims. As noted earlier, Mian et al. (1996) found that young children (ages three to five years) demonstrated similar outcomes to those reported in other research using older or heterogeneous aged samples. However, developmental literature would indicate that an individual may not understand the impact of the abuse at such an early stage without assistance from caregivers or, for later outcomes, from reminders about the events. There is a dearth of longitudinal research following victims for any period after disclosure.

In a study of 82 children and 60 adolescents, Feiring, Taska, and Lewis (1998a, 1998b) found that symptoms following CSA varied by age. Specifically, victims first abused as adolescents were more likely than victims first abused as children to report depressive symptoms and low self-esteem. Also, the adolescent victims reported more depressive symptoms than the child victims but less anxiety regarding sexual issues (feeling that sex is dirty, feeling sex should be avoided). Further, although age was associated with these symptoms (depressive symptoms and sexual anxiety), gender and abuse characteristics (i.e., duration of abuse, victim-perpetrator relationship) were not. These differences are at least partly due to developmental differences between children and adolescents (Feiring et al., 1998a, 1998b). Adolescents are already experiencing many changes and trying to exert their independence which can have an impact on their self-esteem and on internalizing symptoms. Experiencing sexual abuse during this time can cause added stress and make the adolescent more vulnerable to internalizing symptoms (Feiring et al., 1998a, 1998b).

Similar results were found by Gries et al. (2000) when examining children attending psychotherapy who were removed from the home due to abuse and neglect and reported a history of CSA. Older victims (over thirteen years of age) were more likely than younger victims to report depressive symptoms, but younger victims were more likely to experience clinically significant symptoms of PTSD than the adolescents. Although their findings were similar to others, the investigators only sampled a small group (nine adolescents and 12 children) and did not control the age-based differences for differences in duration, severity, victimperpetrator relationship, and support from foster parents. The differences between the older and younger children may actually reflect differences among these other variables of interest. For example more of the adolescents may have been abused more severely or received less support than the younger children. Further, with so small a sample, children or adolescents with extremely elevated scores on the depression or PTSD symptom measures may have unduly impacted the results.

Using parent-report as opposed to self-report for 96 children ages two to 15 years old, Deblinger, Taub, Maedel, Lippmann, and Stauffer (1997) found that age contributed to internalizing outcome, after controlling for gender, victim-perpetrator relationship, severity of abuse, maternal distress, and maternal belief of allegations. Again, older children were more likely to display internalizing symptoms. There was a disproportionately small number of adolescents compared to other age groups, but similar numbers of preschool-aged children and schoolaged children. Contrary to previous studies, Paolucci et al. (2001) did not find significant age-based differences in a meta-analysis. Age was not found to be a predictor of outcome following CSA when all studies included in the analysis were taken together. This included data from 25,367 participants in 37 studies. Conversely, in a review by KendallTackett et al. (1993), age at the time of assessment was found to be of great impact to symptomatology reported, with older children reporting more symptomatology than younger children. It was noted, however, that many studies that reported an age-based difference in outcome failed to control for duration of abuse, severity of abuse, or victim-perpetrator relationship (Kendall-Tackett et al., 1993).

In a review by Beitchman et al. (1991), many discrepancies among studies regarding the effect of age on outcome were noted. Preschool-aged children, in some studies reviewed, showed more sexualized behaviors than their non-abused peers, including sexual play with dolls, masturbation, and sexual knowledge that was not developmentally appropriate. In the review, school-age children were reported to display more academic and behavior difficulties in the school and to show more sexualized behaviors than their nonabused peers. It was 
concluded that younger victims may show more negative outcomes because the duration of abuse is potentially longer and older children and adolescent victims may show more negative outcomes due to the potential use of more force and coercion to maintain the secret. Another explanation may be the interaction between the victim-perpetrator relationship and age, as younger victims are significantly more likely to be abused by a member of their family than are older children and adolescents (Beitchman et al., 1991).

\subsection{Developmental disability}

Children who experience a developmental disability are seen as being at higher risk for sexual abuse (Mansell, Sobsey, \& Moskal, 1998). There is still limited research available to assess what, if any, differences there are among CSA victims with and without developmental disabilities (Balogh et al., 2001). In a sample researched by Balogh et al. (2001), it appeared that, among adolescents with intellectual disability, females were more likely than males to have experienced sexual abuse. Mansell et al. (1998) reported that CSA victims who also have a developmental disability show greater behavioral problems than do victims without developmental disability. Additionally, persons with developmental delays who are sexually abused tend to show a decrease in their physical and cognitive abilities (Mansell et al., 1998).

The effects of CSA on individuals with a developmental disability are assumed to be qualitatively different than those victims without a developmental disability due to fewer coping resources and increased vulnerability to revictimization (Mansell et al., 1998). In comparing CSA victims with and without developmental disability, those with a disability were more likely to exhibit aggressive behaviors, self-abuse, and extreme withdrawal from social interactions (Mansell et al., 1998). Despite these differences, children with developmental disabilities otherwise showed fairly similar outcomes to abuse as those children without developmental disability (Mansell et al., 1998).

\subsection{Attributional style /attribution of blame}

Some researchers have investigated the role that attributions play in the outcome following CSA, suggesting that the victims' attributions regarding the abuse and the attributional style of the individual influences the outcome a victim experiences following abuse (Feiring, Taska, \& Chen, 2002; Kolko, Brown, \& Berliner, 2002; Valle \& Silovsky, 2002). Kolko et al. (2002) report that the victims' attributions are as much a factor in the outcome following abuse as are the characteristics of the abuse. Focusing on the attributions and their relationship to outcome was suggested to benefit treatment interventions, as the cognitive attributions can be targeted and changed, unlike other aspects of the abuse. Many abuse victims had negative attributions about the perpetrator (felt that the perpetrator did not care about them) and about the abuse ("I felt bad when it happened"). Negative attributions about the abuse (i.e., "I think I was abused because of something I did/ didn't do") were related to symptoms of posttraumatic stress disorder in the victims (Kolko et al., 2002).

In an effort to examine the relationship between attributions and symptom-development following abuse, Feiring et al. (2002) investigated the abuse-related attributions of 137 children and adolescents shortly after disclosure and one year post-disclosure. Children who reported more self-blame regarding the abuse were more likely to exhibit stronger internalizing symptoms than those children reporting less selfblame. Additionally, at both the initial data collection and the one year follow-up, children who displayed more internal (to the child) attributions regarding why the abuse happened (e.g., "This happened because of something I did"; "This happened because I was not smart enough to stop it from happening") were more likely to report having intrusive thoughts, avoidance symptoms, hyperarousal, depressive symptoms and lower selfesteem than those children who attributed the abuse to the perpetrator or other external factors. Children with more pessimistic general attributional styles were more likely than those with less pessimistic attributional styles to report depressive symptoms following abuse. The implications that negative internal attributions regarding the abuse may have on children's disclosure of abuse was discussed and it was hypothesized that children with internal attributions about the abuse may delay disclosure because they believe they are at fault for the abuse and additionally may use poor coping strategies, including avoidance, to process their abuse (Feiring et al., 2002).

Mannarino and Cohen (1996) examined the attributional styles and abuse-specific attributions of sexually abused girls compared to sameage peers. The abused girls reported more attributions of feeling different than their peers, blaming themselves for negative events, and believing they were less credible than their peers. The victims' reported symptomatology was highly correlated with negative abuse-related attributions, with victims who endorsed greater negative attributions reporting higher levels of depressive and anxious symptoms and lower self-esteem. The victims' abuse-related attributions accounted for significant proportions of the variance of the victims' symptomatology and were significant predictors of the depressive and anxious symptoms and low self-esteem. Given these data, attributions regarding the abuse should be targeted during treatment.

In a sample of children and adolescents, Feiring et al. (1998a) examined the role that attributional style plays in the short-term outcome following CSA and found that shame and attributional style were moderators for the relationship between symptom outcome and abuse characteristics (age of onset, duration, etc.). Before including shame and attributional style into the regression, adolescents were more likely to report lower self-esteem and depressive symptoms, as were victims who experienced more instances of abuse. Adding variables measuring shame and attributional style to the regression analyses altered the original weight of age and abuse incidents, making them nonsignificant. Shame and attributional style appeared to mediate the effects of age and number of abuse events on outcomes of depression and lower self-esteem. Further, treatment with victims should address the underlying shame and negative attributional style in order to more fully assist the victim in coping with the symptoms experienced following childhood sexual abuse (Feiring et al., 1998a).

\subsection{Treatment following abuse}

Research shows that in general, victims who receive treatment following CSA are more likely to return to pre-abuse functioning sooner than victims who receive no treatment (Kendall-Tackett et al., 1993). For purposes of this review, and due to the potential for impact from experiences other than maltreatment, the discussion of treatment following abuse will be limited to literature examining treatment in childhood following CSA as opposed to treatment of adults victimized as children. In children and adolescents, utilizing group therapy for victims tends to be a popular and effective mode of treatment due to the fact that sexual abuse is cloaked in secrecy and often results in the victim feeling isolated (Heiman \& Ettin, 2001). Results from a one month follow-up study after 11 sessions of treatment, female victims (aged 8-11 years) participating in group therapy showed that the participants and their caregivers felt the treatment had helped (Heiman \& Ettin, 2001).

Having a positive and supportive person with whom the victim can speak openly about the abuse is believed to be important in the recovery process (Gilgun, 1990). In many cases, a therapist or, in the case of group therapy, group members are supportive persons for the victim. As with the girls' group described above, group treatment for boys following sexual abuse can be beneficial (Friedrich, Berliner, Urquiza, \& 
Beilke, 1988). However, following group, the boys continued to show signs of needing longer term treatment than was provided (e.g., selfdestructive behavior, symptoms of anxiety, aggression), as well as more time focused on non-abuse related issues in order to allow the boys to become more familiar with each other, the group process, and the group leaders. This experience led to hypothesizing that the group treatment of male victims has different outcomes than the group treatment of female victims, and that careful consideration must be made when selecting boys for a group (Friedrich et al., 1988).

Regardless of treatment modality, researchers and practitioners have focused on treatment techniques that address the attributions a child has following CSA. In a brief discussion, Cohen and Mannarino (2002) report the importance of allowing a child client to explore and discuss their attributions relating to the abuse, the offender, and themselves. Many children report that they experience guilt related to the abuse, which is an important focus of intervention. These techniques have been utilized with adult victims of rape, and it is believed that similar effectiveness can be expected in their use with child victims (Cohen \& Mannarino, 2002).

In regard to which treatment techniques are especially useful for victims, Saywitz, Mannarino, Berliner, and Cohen (2000) examined existing treatment models and discussed their usefulness and the need for modifying those treatments when utilized with victims of CSA. They note the paucity of research specifically on the treatment of child victims of sexual abuse, but did review available literature. The investigation discovered that cognitive behavioral interventions, coupled with psychoeducational interventions and the incorporation of family members demonstrated decreases in PTSD symptoms, sexualized behaviors, internalizing and externalizing symptoms as well as increased parental support; however, it is important to individualize treatment to the child and family presenting for treatment. The need to include caregivers in the treatment of child victims, both for the impact on the child of the caregiver's support and for the caregiver to manage their own distress following disclosure, is important to consider when addressing treatment needs. Parents' emotional distress following disclosure can impact the symptoms and attributions of the child victim (Mannarino \& Cohen, 1996). In regard to the issue of providing treatment and prevention services to children with asymptomatic responses, it appears that at the least these victims should be provided psychoeducational interventions to limit the likelihood of revictimization, which can also include strategies to ensure the victim does not harbor misperceptions regarding the abuse and may be easily introduced in a group format with other children displaying limited negative outcomes (Saywitz et al., 2000).

In a review of the literature on treatment of children who are CSA victims, Ramchandani and Jones (2003) found that cognitive-behavioral therapy (CBT) was most efficacious in treating the psychological symptoms following abuse. Twelve randomized and controlled studies were examined and CBT interventions including the victim and the non-offending parent showed the most reduction in behavior problems and sexual behavior problems for pre-school children compared to non-directive sessions, supportive therapy, wait-list controls, or child-only interventions. The studies followed various formats, but all utilized pre- and post-intervention measures of depression, anxiety, behavior problems, and trauma symptoms. For older children, the reduction in symptoms was not as great or as consistent across studies as the findings for younger children. Further, group compared to individual delivery format for services was examined, and the only difference found between modalities in terms of symptom reduction was that group treatment seemed to improve self-esteem more than individual treatment (Ramchandani \& Jones, 2003).

Grosz, Kempe, and Kelly (2000) investigated treatment effects for 246 child victims of extrafamilial abuse and their parents across different treatment delivery options. Families were assessed and then referred for appropriate treatment in individual, crisis, family, group, and/or other services based on need. Clinical observations and client feedback were utilized to assess treatment outcomes. The parents reported reduction in distress in themselves and symptoms in their children following receiving group (child and parent), individual (child and parent), and crisis counseling. Also, observations by the research team indicated a reduction in fear, anger, and behavior problems following group and individual treatments. Unfortunately, due to the survey nature of the research, no standardized measures were used to assess changes in the participants and there was no utilization of a control group to examine differences between families in treatment and those who experienced abuse and did not receive treatment.

Bagley and LaChance (2000) examined the treatment effects of an extensive treatment program that included individual, group, and dyadic treatment for 27 victims, their non-offending parents (mothers), and the perpetrators (fathers). The treatment program took, on average, one year to complete and was time and resource intensive (approximately $\$ 10,000$ per family). Treatment followed a humanistic orientation and was designed for the eventual reunification of the perpetrator (father) with the mother and victim. Compared to 30 families who qualified for the program but were not enrolled, those victims in the program showed dramatic decreases in depression and problematic behaviors and an increase in self-esteem. Those victims not enrolled in the program, who also did not receive other treatment, did not show these improvements. Further, the victims enrolled in the treatment program were revictimized by their fathers (the perpetrator enrolled in the program) at a rate of $7 \%$ compared to $20 \%$ of the victims not participating, and the victims in the program were victimized at a rate of $4 \%$ by another perpetrator as compared to $33 \%$ in victims not enrolled in the program. Overall, the intensive program appeared to successfully treat victims, the perpetrators, and the non-offending caregivers and allowed for the reunification of families. There is, unfortunately, no way to compare this treatment program to others due to the unusual nature of the treatment.

In a study comparing 203 randomly assigned victim and nonoffending caregiver dyads to either trauma focused CBT treatment or childcentered treatment, the CBT treatment was found to be much more effective on all measured outcomes (Cohen, Deblinger, Mannarino, \& Steer, 2004). Those in the trauma focused CBT treatment demonstrated reductions in depressive symptoms, PTSD symptoms, shame, and abuse-related attributions as well as improvements in behavior problems. Parents in the CBT treatment reported decreased depression, decreased distress about the abuse, increased support for their child, and more effective parenting. The use of random assignment to treatment type was a unique aspect to this study that contributes to the strength of the investigators' conclusions.

There are many publications on theoretical orientations and approaches to treatment, and on potential treatment strategies that may be useful in treating sexually abused children. Unfortunately, as noted earlier, there is limited literature available regarding treatment outcomes for child victims of CSA. There is a need for much more outcome research on the techniques suggested to be beneficial to child victims and on comparison studies that include different types of treatment and utilize wait-list controls.

\section{Familial factors}

It is important to investigate family variables as other issues within the family can influence outcomes of childhood sexual abuse. Some important familial factors that have been shown to be related to outcome include parental history of CSA, parental responses to disclosure and support of the victim, parental stress and coping, socioeconomic status, and family discord (e.g., Baker, 2001; Deblinger et al., 1997; 
Elliott \& Carnes, 2001; Feiring et al., 1998b; Jankowski, Leitenberg, Henning, \& Coffey, 2002).

\subsection{Parental history of childhood sexual abuse}

Many researchers briefly discuss the impact that a parent's own history of abuse may have on their child's outcome following sexual abuse. Unfortunately, the treatment of a parent's own abuse is cursory in most of the literature. In a review, Beitchman et al. (1991) report that several studies on CSA noted the victims' parent's history of abuse; however, none of the studies reviewed discussed the impact of the parent's abuse on their child's outcome. In a discussion of the effects of abuse on the non-offending parent, McCourt and Peel (1998) found that a parent's history of abuse may not be discussed or processed until their child discloses sexual abuse. It was reported that the parents' child's disclosure may bring up memories and traumatic reactions of their own history of abuse. In a sample of sixteen parents of victims of CSA interviewed on the effects of the abuse on the family, McCourt and Peel (1998) found common themes of guilt and inability to trust.

Following interviews with a sample of nine mothers of CSA victims, who were themselves victims of sexual abuse as children, Baker (2001) reported that a parent's history of CSA had varied effects on their ability to assist their children in coping. Results indicated that the mothers fell into three categories, ranging from being unable to connect their own experiences to their child's experiences to being able to connect their experiences and feelings to their child's experiences and feelings. Responses from the mothers during the interviews suggested that some felt their own abuse blocked them from recognizing their child's abuse, some stated they wanted things to go back to how they were prior to the disclosure by their child, some reported hoping to teach their children protective factors, while others reported that they could connect their own feelings both as a child and a parent to their child's feelings. While important to examine a parent's emotional reaction to their child's abuse, Baker's research does not go on to examine how a mother's own history of abuse affects the way she responds to her child and what the impact is on her child's outcome.

Oates, Tebbutt, Swanston, Lynch, and O'Toole (1998) investigated the impact that a parent's victimization history has on the outcome of a CSA victim by comparing children of 23 mothers with a history of CSA to the children of 44 mothers with no history of CSA (all of the children studied had a history of experiencing CSA). The victims whose mothers had been sexually abused as children did not show vastly differing outcomes from those victims with mothers who were not victims (Oates et al., 1998). Specifically, the children were reported to display similar rates of depression, sadness, and behavioral problems at the initial assessment, 18 months, and five years following the initial assessment, and low selfesteem at 18 months and five years following the initial assessment. The children of victims were reported to have lower self-esteem at the initial assessment than the children of nonvictims. In this study, the investigators did not find that a parent's own history of CSA has a deleterious effect on a child's outcome following sexual abuse.

\subsection{Parental reaction to disclosure/support of the victim}

In a comprehensive review of the literature to examine the reactions of non-offending parents to child disclosure of CSA, Elliott and Carnes (2001) reported that this reaction is related to the adjustment of the child. Further, the support of a parent is a strong predictor of the positive adjustment of the victim following disclosure of abuse, and may be more influential on a victim's adjustment than factors related to the abuse acts. Due to the ability to intervene and change the way a parent supports the victim, the support of a parent may have a greater impact than the abuse related factors on long-term outcomes. In general, the greater the support from parents, the fewer behavioral and emotional difficulties will be displayed by the victim (Elliott \& Carnes, 2001). In one study reviewed, parental support was the best and only predictor of resiliency following CSA (Spaccarelli \& Kim, 1995).

In another review and analysis of research on parent and guardian support following a child's sexual abuse, Bolen (2002) found that the literature suggests that $75 \%$ of nonoffending guardians are supportive of the victim. Four groups of variables were thought to affect caregiver support (characteristics of the guardian, characteristics of the child, characteristics of the abuse, and characteristics of the perpetrator). Caregivers who were more supportive tended to have a second guardian available, have a stronger attachment to the victim, have social support, and have fewer economic stressors. Further, guardians who were emotionally closer to the perpetrator and those that lived in more chaotic homes were less likely to be supportive of the victim. Most studies reviewed did not show a significant impact on support based on caregiver's history of sexual assault. There is the need for further examination of the construct development and measurement of parental and guardian support, especially as the perceived support of a guardian may have an impact on legal proceedings, foster care placement, and the coping of the child victim (Bolen, 2002).

Most mothers offer some support following their child's disclosure; however, the support offered may be ambivalent or inconsistent. Additionally, mothers who may not be emotionally supportive of their children following disclosure may be protective and do all they can to keep their children safe, even if the mothers did not believe their child's disclosure (Elliott \& Carnes, 2001). Conversely, mothers who are punitive and angry toward their child following disclosure tended to have children who displayed greater behavioral problems following CSA and were more likely to have their children removed from the home and placed in foster care (Elliott \& Carnes, 2001).

Feiring, Coates, and Taska (2001) examined attributional style and parental support on development of symptoms following CSA in 130 male and female victims (eight to 15 years of age), and found that those victims that felt supported by their parents reported fewer symptoms, including fewer negative abuse-related attributions, depressive symptoms, and other internalizing symptoms. Also, children who did not feel supported by their parents endorsed more global shame. In families where the mothers did not emotionally support the child following disclosure the perpetrators were more likely to be the primary wage earner for the family and the mothers reported feeling the need to maintain harmony within the family (Feiring et al., 2001).

For 21 children in foster care, support not only impacted the outcomes that the victim experienced, but also whether or not a victim would disclose abuse and not recant a previous disclosure (Gries et al., 2000). Children who felt fully supported by their foster parents reported less depression than those children who felt only partially supported or not supported by their foster parents. Children who felt supported also were more likely to disclose and, following disclosure, displayed fewer externalizing symptoms than those who did not disclose or who recanted their disclosure (Gries et al., 2000).

In another study comparing 32 children placed in foster care to 28 children who remained in the home following disclosure of CSA, Leifer and Shapiro (1995) found that parental support was a factor related to outcome for both groups. For those remaining at home, when their mothers responded to their disclosure with support and increased affection, the victims were reported to function better than those victims whose mothers did not increase affection. Further, those victims whose mothers showed increased affection also showed better coping resources, better social skills, and less emotional distress than the victims whose mothers did not increase their affection. For victims who were placed in foster care following the disclosure of abuse, those whose mothers who were consistent and reliable in their visits showed 
better functioning in regards to behavior problems and overall maladjustment, according to their foster mothers (Leifer \& Shapiro, 1995).

Some researchers feel that the family environment, including a parent's response to the disclosure of CSA and the support given to the victim, is potentially more influential on outcome than the factors related to the abuse itself, if only because these family variables are potential targets for intervention, whereas the abuse characteristics are immutable (Deblinger, Steer, \& Lippman, 1999). In general, the literature suggests that victims who receive support from their nonoffending parents are less symptomatic than those victims that receive no support. In a sample of 100 children referred for therapeutic services following CSA, Deblinger et al. (1999) found that children who reported that their mother's parenting style was rejecting rather than accepting were more likely to report greater symptoms of depression. Further, those children who reported that their mothers used parenting strategies that incorporated guilt and shame also reported greater symptoms of PTSD, and their parents reported more externalizing symptoms in the victims. These findings suggest that maternal adjustment and parenting style contribute to a child's adjustment following CSA, and interventions to address the adjustment and parenting style will likely influence the symptomatology of the child victims (Deblinger et al., 1999).

Bolen and Lamb(2007) found that only externalizing and delinquent behaviors were related to parental support (with less support being related to greater difficulties in these areas). Contrary to other findings reported below regarding a parent's ability to support a child who discloses CSA, Bolen and Lamb found that greater life stressors led to greater support by the parent. Children in this study who reported greater attachment to their parents also reported less anger and fewer symptoms (Bolen \& Lamb, 2007). This attachment was a greater predictor of outcome than parental support. Feiring et al. (1998b) found that parental support was the only variable that explained depressive symptoms in victims, with the greater perceived parental support, the fewer depressive symptoms reported. Further, children rather than adolescents were more likely to report high levels of parental support following disclosure and to be more satisfied with the support they received. Teens were more likely to report support from peers, but this support, unlike parental support, was related to greater psychological distress (Feiring et al., 1998b).

On a more negative note, some researchers have discovered that a parent is less able to be supportive of their child due to the parent feeling anger or blame toward the child or not believing the child. Parents may focus anger at the victim for various reasons, including the child's delay to disclosure, the child's choice to disclose to someone other than the parent, and the resulting dissolution of a marriage, among others (McCourt \& Peel, 1998). This anger toward the child makes it more difficult for the parent to be supportive of the child. Another factor that may result in the inability of a parent to provide support for their child is when the parent does not believe the child's allegations of abuse. Deblinger et al. (1997) report that when children showed few negative responses to alleged abuse, the parent was less likely to believe the allegations, and in turn less likely to support the child. It was noted that it is impossible to discern if the parents' reporting that the child displays no symptoms is due to their disbelief of the abuse allegations, or if the lack of symptomatology leads a parent to disbelieve the allegations (Deblinger et al., 1997). Further, Mian et al. (1996) note that mothers of children abused by someone within the family were more likely to blame the victim, be supportive of the perpetrator, be more concerned with the impact of the abuse on themselves, and be less likely to believe the child's allegations than mothers of children with extrafamilial perpetrators.

\subsection{Parental distress, mental health, and coping}

Following directly from the impact that the support of a parent can have on a CSA victim's adjustment is the question: what influences a parent's ability to be supportive to the victim? While there are many factors that influence a parent's ability to provide their child with support following the disclosure of CSA, the distress that a parent feels following disclosure, their mental health status, and their ability to cope will impact the support they are able to give. Parents with significant depression were more likely to report PTSD and externalizing symptoms in their children and were less likely to be emotionally available for their children following disclosure of sexual abuse (Deblinger et al., 1997). Further, when a victim perceived that his/her mother was rejecting, greater depressive symptoms were reported. Similarly, those victims that reported that their mother utilized parenting styles that were guilt triggering were more likely to report symptoms of PTSD (Deblinger et al., 1999). There is no way to discover a causal relationship between maternal depression and child's outcome, and the results may be due to the parent reporting greater symptoms in their children due to their own psychological distress, or that the children, through their interactions with depressed parents, develop more psychological symptoms than their peers (Deblinger et al., 1999).

Davies (1995) reported that factors ranging from parent's depressive symptomatology to parent's report of satisfaction with the parent/child relationship affected the parent's ability to cope with the reported abuse. Specifically, parents fell into three categories regarding their ability to cope following disclosure: parents who were able to cope following a period of distress, parents able to cope following distress but with difficulty, and parents unable to cope with the abuse. The parents unable to cope with their child's abuse were more likely to have difficulties in their relationships with their partner and the abused child, have symptoms of depression, PTSD, and anxiety. Parents who were unable to cope with their child's abuse were more likely to not trust their child, and in turn their child showed poorer adjustment following abuse (Davies, 1995).

\subsection{Family stress (economic and relational)}

Family stress can influence the way a child adjusts to sexual abuse. Mannarino and Cohen (1996) found in general, mothers in families where there was a child with a history of CSA were more likely to report low family cohesion regardless of whether the perpetrator was a member of the family or not. Children in families reported to be low in family cohesion reported low social competence, which may suggest that these victims are not able to find support within or outside of the family in away that met their needs. Parents who experience extremely negative emotions may be less able to support their children due to the need to cope with their own negative emotions. Mothers that reported greater negative emotions also reported more behavior problems and internalizing symptoms in their children. The influence of these negative emotions may be that the children feel to blame for the abuse and the disclosure and the impact that their abuse had on their parent (Mannarino \& Cohen, 1996).

Further complicating the picture following CSA is the role of the economic status of the family. When the perpetrator is a family member, especially a parent or parent figure, there may be an additional financial consequence (loss of the perpetrator's income) following disclosure that can cause additional stress for the family and the nonoffending parent. Family members may blame the victim for the loss of income and the results of that loss (i.e., loss of a home, having to move in with others) (Fischer \& McDonald, 1998). Another potential consequence is that the abuse is not reported to the authorities due to the need to keep the perpetrator's financial contribution to the household. This can lead to further abuse, guilt, and feelings of worthlessness for the victim. The nonoffending parent may be unwilling to protect the victim due to fear of the perpetrator leaving and the financial ramifications associated with the loss of income.

In a sample of 329 homeless adolescents, Ryan, Kilmer, Cause, Watanabe, and Hoyt (2000) reported that adolescents with a history 
of abuse were more likely than adolescents with no history of abuse to report having a parent who abused alcohol and/or drugs and who provided little emotional support. Further, family characteristics (i.e., support from caregiver, drug and alcohol use by caregiver, criminal justice history of caregiver) were more predictive of externalizing problems than prior abuse (Ryan et al., 2000). The stress present in a family seems to impact not only the victim and their adjustment, but also the ability of other family members to respond in a caring and nurturing way to the victim's needs.

Many researchers only briefly report demographic information regarding family stressors in their reports. For example, Beitchman et al. (1991) reported that families in several studies reviewed were likely to be labeled as "disorganized" as evidenced by parental alcoholism, divorce, and other stressors (Adams-Tucker, 1981 as cited in Beitchman et al., 1991), likely to have emotionally distant parents and family secrets (e.g., extramarital affairs) (Smith \& Israel, 1987), and likely to have difficult parent-child relationships and stressors in the family (Friedrich \& Luecke, 1988). Deblinger et al. (1999) also note that greater family conflict was associated with behavioral symptoms in victims following sexual abuse in their study of 100 victims and their nonoffending parents. Victims whose mothers reported greater distress and used pejorative parenting reported greater depression and PTSD symptoms (Deblinger et al., 1999). In contrast, Stern et al. (1995) found that, after controlling for abuse severity, the level of family functioning was not significantly related and questioned the focus in treatment on this aspect of functioning.

In a review, Kendall-Tackett et al. (1993) report that families where there is much strain, little support, and anger resulted in more symptoms following CSA. Additionally, it was the dysfunctional environment, rather than the abusive experience itself, that was hypothesized, but not investigated, by some of the authors reviewed (i.e., Clausen \& Crittenden, 1991 as cited in Kendall-Tackett et al., 1993) to produce the trauma and symptomatology following CSA, while other authors (i.e., Conte \& Schuerman, 1987) have research evidence that the environment plays a large role in the way an abusive experience contributes to the child's symptomatology. In general, it is suggested that outcomes are related to the abuse experience and how that experience interacts with the family environment and the response of others to the abuse, with victims in a family with little dysfunction and adequate support having better recovery than those in families with much dysfunction and little support (Kendall-Tackett et al., 1993). Further, Hebert, Tremblay, Parent, Daignault, and Piche (2006) found a significant correlation between family cohesiveness and family conflict and a child's symptomatology following sexual abuse.

Some evidence has contradicted the suggestion that family dysfunction accounts for the symptoms following CSA. In a study of college students by Steel, Wilson, Cross, and Whipple (1996) examining 264 nonvictims and 115 CSA victims, family dysfunction did not account for the symptom differences reported by abused versus nonabused participants. However, these findings may not represent the pattern for most abused children, as the data were collected retrospectively from a sample of college students, who may function at a higher level than victims that do not attend college, and who may have families with less dysfunction than other victims. Additionally, there was no way to ascertain what level of abuse the participants experienced, as most reported less than five occurrences, and the severity of the abuse was unable to be determined.

\subsection{Treatment of parents and other family members}

As noted earlier, the support of a caring individual can help mediate the effects of CSA. One way to assist caregivers and other individuals important to the victim in being supportive is through therapy provided directly to those individuals. In a pilot study following the changes in psychological symptoms in 16 victims and their 18 caregivers following therapeutic services for the nonoffending parents and/or individual treatment for the victim, it was shown that these interventions had a significant impact on both caregivers and victims (Forbes, Duffy, Mok, \& Lemvig, 2003). Following these interventions, the children were reported to have fewer sexual behavior difficulties and the parents reported fewer psychological symptoms and emotional reactions in themselves. Further investigation, using a larger sample size, is necessary to analyze the veracity of these claims and to elucidate which factors are influencing these changes, whether it is the treatment of the child or the changes in the parental support due to the parent's treatment.

In an examination of the treatment effects of 246 children and their 323 parents, Grosz et al. (2000) found that parental involvement in treatment had a positive impact on victim symptomatology. The treatment consisted of supportive groups for the parents, groups for the child that incorporated coping strategies, prevention education, and support, crisis counseling including assessment for future services, and individual counseling for the child. Specifically, treatment in one or more treatment modalities of different durations (one session to 24 months) resulted in fewer observed and reported depressive, fearful, aggressive, and sexualized behavior symptoms in children and a reduction of depressive, fearful, anxious, and guilty symptoms in their caregivers. Unfortunately, standardized measures were not utilized and results relied on observation and satisfaction surveys. Thus, it was difficult for them to reliably measure changes in symptoms in the victims and their caregivers.

Corcoran and Pillai (2008) reported that a meta-analysis of seven studies indicated small to moderate effect sizes for parent-involved treatment on a child's outcome following CSA. While this is not a clear stamp of approval for this type of treatment, it does indicate that involving non-offending parents in the treatment of victims of CSA is not harmful and may benefit some children and families.

\section{Abuse-specific factors}

Factors specific to the abuse, including abuse duration, abuse severity, and the relationship between the victim and the perpetrator can have a significant impact on the outcome that a victim experiences. Although these factors are not amenable to change, it is important to understand their impact on the victim to assist in predicting potentially helpful therapeutic interventions for the victim and the family.

\subsection{Abuse severity}

Abuse severity is often discussed as the type of abuse that a victim was subjected to. Frequently, abuse that includes some type of penetration (oral, vaginal, or anal) is considered particularly severe, while abuse that does not involve contact (e.g., exposure, pornography, sexual talk) is considered less severe (Kendall-Tackett et al., 1993). However, other factors that contribute to the severity of abuse are the use of force and/or weapons during the abusive acts, physical abuse of the victim, and threats by the perpetrator against the victim or the victim's family. As noted in previous sections, the definition of sexual abuse is not universal, and that includes the differentiation between severity levels of abuse (Paolucci et al., 2001). One difficulty in discussing the relationship between severity of abuse and outcome is that different researchers use different categories to describe severity during examination of symptoms. Also, severity of abuse is often defined in part by the duration of abuse and the victim- perpetrator relationship. It is extremely difficult to tease apart the independent contribution of these factors on outcome following CSA.

Paolucci et al. (2001) found that severity of abuse, broadly defined as contact vs. noncontact, did not mediate the effect of CSA on PTSD symptoms, depression, suicide attempt, sexual promiscuity, or academic difficulties. It should be noted that his finding does not replicate findings in earlier studies that suggest abuse severity is related 
to negative outcome, with victims who experience more severe abuse showing greater negative symptoms, which may be the result of definitional issues in reporting the severity of abuse.

In a review, Beitchman et al. (1991) note that several studies found that the more severe the acts of abuse, the more likely a child is to demonstrate negative symptomatology following sexual abuse. Specifically, sexual abuse that involves penetration and/or violence, threats, and force is more likely to lead to negative outcomes for the victim (Beitchman et al., 1991). Similarly, in a study of 106 victims, Fergusson, Lynskey, and Horwood (1996) noted that the more severe abuse a child experienced, the more likely that child was to experience depressive symptoms, anxious symptoms, conduct problems, substance use and abuse, and attempted suicide. For those victims that experienced intercourse, $64 \%$ showed symptoms of depression, versus $50 \%$ for victims that experienced no contact, or contact without intercourse as the most severe form of abuse (these differences were significant; $p<$ 0.0001). Thirty-three percent of those victims with the highest severity of abuse (intercourse) attempted suicide at some time, compared to $4 \%$ for victims of noncontact abuse, and $11 \%$ for victims of abuse consisting of contact with no intercourse (these differences were significant; $p<0.0001)$. Even following control for other familial factors, victims of the highest severity of abuse continued to show the highest rates of depressive symptoms, anxious symptoms, conduct problems, substance use, and attempted suicide compared to other victims of CSA. A particular strength of the Fergusson et al. (1996) study was the use of a longitudinal design, following a cohort of children over 18 years, and comparing children with a history of CSA to those with no history, but who had other similar life experiences.

In contrast to Fergusson et al. (1996), Manion et al. (1998) discovered that severity of abuse was not significantly predictive of outcome for the victim nor was it related to the parent's report of their own symptoms either immediately post-disclosure or one year following disclosure. All of the victims were abused for less than one year by someone outside the family or a distant relative, however, which may have an impact on the severity of abuse experienced. It is unclear whether these results would generalize to children who experienced more severe abuse. Unfortunately no specific data were provided regarding the extent of abuse.

\subsection{Duration of abuse}

The duration of abuse can have an impact on the outcomes a victim experiences. In general, the longer that a victim is abused or the more abuse incidents that a victim experiences, the more likely the victim is to experience a negative outcome (Finkelhor \& Dziuba-Leatherman, 1994; Kendall-Tackett et al., 1993). In a study of 90 children recruited shortly following disclosure, Wolfe, Sas, and Wekerle (1994) found that duration contributed to the victims' outcome, with more children who were abused for long durations (over one year) displaying PTSD symptoms. Further, results indicated that duration, age, and gender were the only studied variables which differentiated victims experiencing PTSD symptoms from those that did not, and frequency of abuse, severity of abuse, and relationship of offender to victim did not distinguish the victims with regard to PTSD symptoms (Wolfe et al., 1994). In another study using a child sample, Hebert et al. (2006) found length of abuse to be significantly correlated with outcomes, such as sexualized behaviors, symptoms of anxiety and depression, and aggression.

Feiring, Rosenthal, and Taska (2000) noted that, for the adolescents studied, the only abuse-specific factor related to peer relationships was number of abuse incidents. Adolescents who experienced more abuse events were less likely to feel accepted by peers and less likely to feel they appealed to others, although these relationships did not reach significance. Similarly, Steel et al. (1996) found that, in a college sample of victims, the more frequent and longer duration of the abuse events, the more likely that the victim would display clinically significant symptomatology.

\subsection{Victim-perpetrator relationship}

The relationship between the perpetrator and the victim, which can affect the outcome that a victim experiences following CSA, is often described as intrafamilial (related through blood or marriage) or extrafamilial (not related, outside of the family). In general, it is believed that the closer the victim-perpetrator relationship, the more severe the impact on the child (for a review see Kendall-Tackett et al., 1993; for alternate results see Paolucci et al., 2001). The logic appears to be that most researchers determine that an intrafamilial relationship will be a closer relationship than an extrafamilial relationship. However, as Kendall-Tackett et al. (1993) point out, the label that a relationship is given may not truly reflect the nature of the relationship. For example, a child who is abused by their stepfather who has been the only father she has known may have a much closer relationship to his/her perpetrator than a child who is abused by a stepfather who he/she has only known a short time. Measuring the closeness of the relationship, rather than the category the relationship falls into, will give a more accurate description of the nature of the relationship and the potential impact it may have on the outcome following the abuse. Further complicating the picture is the fact that perpetrators who are close in relationship with the victim often have more access to the child, which in turn may impact the severity and duration of the abuse. In a review of 1037 cases of substantiated sexual abuse, it was reported that intrafamilial abuse more often involved younger victims, more physical injury to the victim, longer abuse duration, and more severe acts of abuse, whereas extrafamilial abuse was more likely to involve physical force (Fischer \& McDonald, 1998). Further, many researchers have failed to offer proof of a significant difference in outcome between victims of intrafamilial and extrafamilial abuse.

Wolfe et al. (1994) discovered that the victim-perpetrator relationship was not significantly related to the development of PTSD symptoms for the 90 victims participating. However, those children that were abused for longer durations were more likely to exhibit PTSD symptoms, and there was no information on whether these are also children who were abused by perpetrators with whom they had a close relationship. It was noted that more of the victims who were abused by a parent, stepparent, or extended family member displayed PTSD symptoms than those who were abused by strangers and non-family members (Wolfe et al., 1994).

In a review, Beitchman et al. (1991) found that most reviewed literature suggested a correlation between the victim-perpetrator relationship and the outcome that a victim experienced. Those victims who were abused by their father or stepfather were more likely to show trauma symptoms than those abused by other offenders. Additionally, these victims also evidenced more symptoms of depression and withdrawal. In contrast, some studies reviewed found no differences between victims of intrafamilial versus extrafamilial abuse in severity or type of symptoms displayed. Of importance to note, in the studies reviewed, the age and gender of the child were closely related to, and may confound, the relationship to the perpetrator, with girls and younger victims more likely to have been the victim of intrafamilial abuse (Beitchman et al., 1991). In turn, the more severe impact noted to be associated with relationship to perpetrator might actually be related to the age and gender of the victim and the duration and severity of the abuse.

While investigating preschool children, Mian et al. (1996) again found that the duration of abuse was longer with victims of intrafamilial abuse, but that there was no significant difference between the groups on internalizing or externalizing symptoms. Victims of intrafamilial abuse demonstrated less social skill and fewer anxious symptoms than the 
victims of extrafamilial abuse. Similarly, Stern et al. (1995) found that intrafamilial abuse was not related to greater depressive symptoms, lower self-esteem, or more behavior problems. However, it was noted that victims of intrafamilial abuse were more likely than those of extrafamilial abuse to experience a disruption in parenting and to not live with both parents. Also, the victims of extrafamilial abuse tended to be abused for shorter periods of time, less frequently, and disclosed sooner than those abused by someone in their family (Stern et al., 1995). Hebert et al. (2006) also found that children ages seven to 12 who were abused by someone in their immediate or extended family displayed more significant internalizing and externalizing symptoms than those victimized by someone with whom they had a less close relationship.

Lucenko, Gold, and Cott (2000) examined the victim-perpetrator relationship and the impact on long-term outcome of 67 women who reported a history of CSA. The results indicate that the relationship between the victim and perpetrator showed converse results from what was expected. Specifically, those victims abused by someone not in a caretaker role reported more trauma related symptoms. It was speculated that the reported symptoms are related to the higher incidences of physical abuse reported by the victims of non-caregivers during the abuse acts. Perhaps the perpetrators that were not in a care taker role for the victim had fewer qualms about engaging in more extreme abusive acts against the victim which in turn resulted in more severe abuse and greater trauma symptoms. However, it should be noted that this study utilized a sample of victims that were attempting to access treatment services. These victims likely are qualitatively different from adult victims that are not requesting therapeutic services. The results further demonstrate that the label of the victim-perpetrator relationship is not as important as the quality of that relationship (Lucenko et al., 2000).

Contrary to the results by Lucenko et al. (2000), Ketring and Feinauer (1999), in a study of 475 adult victims, found that those victims abused by a father figure reported greater trauma symptomatology than those abused by other family members and non-family members. Further, those victims of abuse by other family members reported more trauma symptoms than victims of abuse by strangers. The quality of the relationship between the victim and the perpetrator was examined by asking the respondents about their feeling regarding their perpetrator prior to the onset of the abuse. Results did not support the hypothesis that the closer the victim felt to the perpetrator, the greater the severity of outcome. Regardless of the perceived quality of the relationship to the perpetrator, those victims abused by a father or father figure reported greater trauma symptomatology (Ketring \& Feinauer, 1999). Aside from the obvious ramifications of utilizing the retrospective report of the quality of a relationship prior to the experience of abuse, the respondents were only asked one question regarding their feelings toward the perpetrator prior to the abuse. Answers from the respondents were categorized into six categories (positive, negative, ambivalent, positive and negative, positive and ambivalent, and negative and ambivalent), which were used in the analyses. Although the importance of the quality of the relationship over the label given to the relationship was recognized, there was no comprehensive evaluation of the nature of the relationship or examination of the change in that relationship following the abuse.

\section{Future research}

There have been few comprehensive studies that have examined all or most of the factors that the literature suggests contribute to the outcomes that a victim experiences following CSA (for comprehensive reviews see Kendall-Tackett et al., 1993; Paolucci et al., 2001). Most studies have focused on specific factors (i.e., victim-perpetrator relationship, demographic characteristics of the victim, severity of the abuse) while ignoring other factors that are likely influencing the symptoms measured. Many studies focus on the static factors related to the abuse (e.g., duration, severity, demographic characteristics) and do not collect data on the factors that are amenable to change (e.g., parental support, attributions, treatment). Additionally, many researchers fail to investigate victims that show asymptomatic responses following CSA, or if they do research with this population, those findings are not reported in the literature.

The static factors of the abuse experience are unchangeable. However, there are therapeutic interventions available to ameliorate symptoms by focusing on those factors that are amenable to change (Bagley \& LaChance, 2000; Cohen et al., 2004; Grosz et al., 2000). Further, by examining victims that exhibit asymptomatic or minimal negative outcomes, the protective factors that are likely present in those children can be incorporated into treatment with victims that display a more negative outcome. To date there has been little published research specifically examining these children with asymptomatic or minimally negative outcomes and the factors that contribute to their responses.

Future research should focus on including more of the factors that influence the outcome that a victim experiences. Research incorporating personal factors, family factors, and abuse-related factors will provide a clearer picture of why victims experience differing outcomes following CSA, including asymptomatic responses. Additionally, the timing of data collection is equally important to examining these multiple factors in order to gain more insight to the responses of victims. Data that are collected years after the occurrence of CSA makes it difficult to attribute any findings to the sexual abuse versus the many other events in the victim's life since the abuse occurred.

\subsection{Limitations and inherent difficulties in CSA research}

Due to the difficulty in parsing out the effects of the abuse events, other stressors, and personal factors, research on sexual abuse outcomes can never definitively prove that a symptom displayed by a victim is a result of the abuse or some other factor. Similarly, it is usually impossible to gather information from a sample prior to those individuals experiencing abuse, and recollections of pre-abuse functioning are likely influenced by factors related to the abuse and other developmental changes.

When using samples of adults with a history of CSA, it is likely that these victims' interpretations of the events and their recollections of important details (i.e., support from others, immediate symptomatology) are not as accurate as if data were collected soon after the abuse and may be influenced by other events, information from others, and the portrayal of victims in the media and entertainment. Knowing that data collection on abuse-specific factors is likely more accurate the closer to the event does not make actual data collection easy. Many times an adult sample is much easier to collect and can provide information on outcome from a more longitudinal point of view. It is often difficult or impossible to collect data on a large enough sample when using children and adolescents and their families and many studies using a child or teen sample have an extremely small number of participants. Many families are so distraught that it creates significant practical and ethical challenges for investigators who hope to gather data on recently abused victims. Also, institutional review boards are often reluctant to grant approval to collect data of this sensitive nature from children and families. Unfortunately, these limitations also limit the ability of professionals to discover important points of intervention that can have a substantial impact on the victims and on future intervention efforts with other victims and make it more difficult to understand the long-term consequences of abuse.

Aside from these difficulties in data collection, there are inherent difficulties that arise from any study of victim outcome. Because there are often no data available on many victims on variables of interest prior to the abuse, it is impossible to understand the unique impact of the 
abuse and the outcomes following the abuse. Longitudinal cohort investigations in which data is collected over time for a group of children could provide more insight into the unique impact of abuse by utilizing data collected prior to the abuse and by having a comparison group available, but these studies are difficult and expensive to conduct.

Further complicating research in this area is the fact that there are also no universal definitions for what constitutes sexual abuse, and researchers can define sexual abuse in very broad, very narrow, or more moderate terms (Goldman \& Padayachi, 2000; Haugaard, 2000; Mannon \& Leitschuh, 2002). For example, a researcher can choose to include only those children who were abused by an adult and not those abused by another child or adolescent, or the researcher can include similar-age peers and developmentally normal experimentation in the definition of abuse for their study (Goldman \& Padayachi, 2000; Haugaard, 2000; Mannon \& Leitschuh, 2002).

The heterogeneity of the victim population makes it difficult to examine whether measured outcomes are a result of the abuse or other life events. Childhood sexual abuse is found in all ethnic, age, and socioeconomic groups, in both rural and urban settings, and in both dysfunctional and healthy families. This can create widely disparate historical contexts for the victims. It is difficult to separate these factors from the abuse-specific factors when studying the effect of CSA. Often times, these factors are confounding variables on symptoms following outcomes and may have a greater impact than the abuse itself.

Along with the heterogeneity of the victim population, the widely differing responses to the sexual abuse make it difficult to generalize findings. Children and adolescents can show vastly differing outcomes, even in the face of similar historical and abuse characteristics (Kendall-Tackett et al., 1993). Outcomes can range from asymptomatic responses to severe responses including PTSD symptoms and suicidal ideation and attempts. Additionally, victims can show different responses at different developmental stages following abuse, including differing responses into adulthood.

Another difficulty in conducting research with victims is the many available measures to assess symptomatology. Sexual abuse does not result in a specific pattern of symptoms; therefore, researchers often use multiple measures to gather data on victim outcome. The resulting problem is that researchers choose their measures and their results may not be easily compared to another researcher who chose a different measure to assess a specific dimension or chose to assess different dimensions. Along similar lines, some researchers may choose to only gather data on the abuse characteristics, demographic data on the victim, and a parental assessment of the youth's symptomatology. This is especially problematic for teens, who are often more accurate reporters of their feelings than are their parents (Hope, Adams, \& Reynolds, 1999). A more comprehensive data collection is necessary to gather sufficient data to thoroughly examine the outcomes a victim displays. Self-report of feelings, attributions, and support from others needs to be gathered as well as caregiver report of symptomatology, expectations for the child's future, family variables, and caregiver reaction to gain a more comprehensive picture of the abuse and outcomes. Further, longitudinal data collection will assess other factors that contribute to long-term outcome, including treatment received and developmental changes.

\section{Conclusions}

There are many factors related to the outcome that a victim experiences following childhood sexual abuse. These factors can be grouped according to whether they are factors related to the child, the family, or the abuse events. Keeping in mind the limitations of research in this area, the literature suggests that, in general, female victims are more likely to experience internalizing symptoms, male victims are more likely to experience externalizing symptoms, younger children are more likely to be abused for a longer duration, while adolescents may have more insight into what the abuse means. The attributional style and the attributions that a victim has regarding the abuse can have a significant impact on the outcome a victim experiences. Those victims that perceive that they are to blame for the abuse are more likely to experience negative outcomes.

For familial factors (e.g., parent's history of abuse, parental support of the victim, parental mental health, and family functioning), results from the literature are again mixed, but most researchers agree that parental support is a significant predictor of victim outcome. Further, a parent's distress and own mental health difficulties may impact their ability to provide support to their child. The victim's outcome can also be influenced by the family functioning prior to and after the abuse is disclosed.

Abuse-specific factors (i.e., relationship between the victim and perpetrator, the duration of the abuse, and the severity of the abuse) are considered static and thus not amenable to change through intervention. Research shows that the longer and more severe the abuse, the more likely the victim is to experience negative outcomes. Results regarding the impact of victim-perpetrator relationship are quite divergent, with some reporting that extrafamilial abuse is more damaging, some reporting that intrafamilial abuse is more damaging, and others finding no difference based on relationship between the victim and perpetrator.

Despite knowing many factors that contribute to the outcome that a victim, there are still questions of how those factors interact, which are more significant in influencing outcome, and how we can effectively intervene to assist those victims that are experiencing psychological distress following abuse. Some of the factors, such as treatment following abuse, parental support, attributional style, and family functioning can operate as protective factors. In this sense, a victim who experiences significant abuse over a long time may still experience a more moderate outcome if that victim has support from a caregiver, is provided treatment, and is able to place responsibility on the perpetrator. As we learn more about these protective factors, we can attempt to intervene in these areas to assist those victims that are experiencing more negative outcomes.

\section{References}

Bagley, C., \& LaChance, M. (2000). Evaluation of a family-based programme for the treatment of child sexual abuse. Child and Family SocialWork, 5, 205-213.

Baker, L. J. (2001). Multigenerational sexual abuse: A cognitive developmental approach to understanding mothers in treatment. Journal of Adult Development, 8, 51-59.

Balogh, R., Bretherton, K., Whibley, S., Berney, T., Graham, S., \& Richold, P. (2001). Sexual abuse in children and adolescents with intellectual disability. Journal of Intellectual Disabilities Research, 45, 194-202.

Beitchman, J. H., Zucker, K. J., Hood, J. E., DaCosta, G. A., \& Akman, D. (1991). A review of the short-term effects of child sexual abuse. Child Abuse \& Neglect, 15, $537-556$.

Berliner, L., \& Elliott, D. M. (1996). Sexual abuse of children. In J. Briere \& L. Ber liner (Eds.), APSAC handbook on child maltreatment, (pp. 51-71). Thousand Oaks CA Sage Publications, Inc.

Bolen, R. (2002). Guardian support of sexually abused children: A definition in search of a construct. Trauma, Violence, \& Abuse, 3, 40-67.

Bolen, R. M., \& Lamb, J. L. (2007). Parental support and outcome in sexually abused children. Journal of Child Sexual Abuse, 16(2), 33-54.

Browne, A., \& Finkelhor, D. (1986). Impact of child sexual abuse: A review of the research. Psychological Bulletin, 99, 66-77.

Chandy, J. M., Blum, R. W., \& Resnick, M. D. (1996). Gender-specific outcomes for sexually abused adolescents. Child Abuse \& Neglect, 20, 1219-1231.

Cohen, J. A., Deblinger, E., Mannarino, A. P., \& Steer, R. A. (2004). A multisite, randomized controlled trial for children with sexual abuse-related PTSD symptoms. Journal of the American Academy of Child and Adolescent Psychiatry, 43, 393-402.

Cohen, J. A., \& Mannarino, A. P. (2002). Addressing attributions in treating abused children. Child Maltreatment, 7, 82-86.

Conte, J. R., \& Schuerman, J. (1987). The effects of sexual abuse on children: A multidimensional view. Journal of Interpersonal Violence, 2, 380-390. 
Corcoran, J., \& Pillai, V. (2008). A meta-analysis of parent-involved treatment for child sexual abuse. Research on SocialWork and Practice, 18, 453-464.

Davies, M. G. (1995). Parental distress and ability to cope following disclosure of extrafamilial sexual abuse. Child Abuse \& Neglect, 19, 399-408.

Deblinger, E., Steer, R., \& Lippman, J. (1999). Maternal factors associated with sexually abused children's psychosocial adjustment. Child Maltreatment, 4, 13-20.

Deblinger, E., Taub, B., Maedel, A. B., Lippmann, J., \& Stauffer, L. B. (1997). Psychosocial factors predicting parent reported symptomatology in sexually abused children. Journal of Child Sexual Abuse, 6, 35-49.

Elliott, A. N., \& Carnes, C. N. (2001). Reactions of nonoffending parents to the sexual abuse of their child: A review of the literature. Child Maltreatment, 6, 314-331.

Feiring, C., Coates, D. L., \& Taska, L. S. (2001). Ethnic status, stigmatization, support, and symptom development following sexual abuse. Journal of Interpersonal Violence, 1307-1329.

Feiring, C., Rosenthal, S., \& Taska, L. (2000). Stigmatization and the development of friendship and romantic relationships in adolescent victims of sexual abuse. Child Maltreatment, 5, 311-322.

Feiring, C., Taska, L., \& Chen, K. (2002). Trying to understand why horrible things happen: Attribution, shame, and symptom development following sexual abuse. Child Maltreatment, 7, 26-41.

Feiring, C., Taska, L., \& Lewis, M. (1998a). The role of shame and attributional style in children's and adolescent's adaptation to sexual abuse. Child Maltreatment, 3, $129-142$.

Feiring, C., Taska, L. S., \& Lewis, M. (1998b). Social support and children's and adolescents' adaptation to sexual abuse. Journal of Interpersonal Violence, 13, 240-260.

Fergusson, D. M., Lynskey, M. T., \& Horwood, L. J. (1996). Childhood sexual abuse and psychiatric disorder in young adulthood: II. Psychiatric outcome of childhood sexual abuse. Journal of the American Academy of Child and Adolescent Psychiatry, 34, $1365-1374$.

Finkelhor, D., \& Browne, A. (1985). The traumatic impact of child sexual abuse: A conceptualization. American Journal of Orthopsychiatry, 55, 530-541.

Finkelhor, D., \& Dziuba-Leatherman, J. (1994). Victimization of children. American Psychologist, 49, 173-183.

Fischer, D. G., \& McDonald, W. L. (1998). Characteristics of intrafamilial and extrafamilial child sexual abuse. Child Abuse \& Neglect, 22, 915-929.

Forbes, F., Duffy, J. C., Mok, J., \& Lemvig, J. (2003). Early intervention services for nonabusing parents of victims of child sexual abuse. British Journal of Psychiatry, $183,66-72$.

Friedrich, W. N., Berliner, L., Urquiza, A. J., \& Beilke, R. L. (1988). Brief diagnostic group treatment of sexually abused boys. Journal of Interpersonal Violence, 3, $331-343$.

Friedrich, W. N., \& Luecke, W. J. (1988). Young school-age sexually aggressive children. Professional Psychology: Research and Practice, 19, 155-164.

Gilgun (1990). Factors mediating the effects of childhood maltreatment. The sexually abused male. In M. Hunter (Ed.), Prevalence, impact, and treatment, Vol. 1. (pp. 177-190) Lexington, England: Lexington Books.

Goldman, J. D. G., \& Padayachi, U. K. (2000). Some methodological problems in estimating incidence and prevalence in child sexual abuse research. Journal of Sex Research, 37, 305-315.

Gries, L. T., Goh, D. S., Andrews, M. B., Gilbert, J., Praver, F., \& Stelzer, D. N. (2000). Positive reaction to disclosure and recovery from child sexual abuse. Journal of Child Sexual Abuse, 9, 29-51.

Grosz, C. A., Kempe, R. S., \& Kelly, M. (2000). Extrafamilial sexual abuse: Treatment for child victims and their families. Child Abuse \& Neglect, 24, 9-23.

Haugaard, J. J. (2000). The challenge of defining child sexual abuse. American Psychologist, 55, 1036-1039.

Heath, V., Bean, R., \& Feinauer, L. (1996). Severity of childhood sexual abuse: Symptom differences between men and women. The American Journal of Family Therapy, $24,305-314$

Hebert, M., Tremblay, C., Parent, N., Daignault, I. V., \& Piche, C. (2006). Correlates of behavioral outcomes in sexually abused children. Journal of Family Violence, 21, 287-299.

Heiman, M. L., \& Ettin, M. F. (2001). Harnessing the power of the group for latency-aged sexual abuse victims. International Journal of Group Psychotherapy, 51, $265-282$.

Hope, T. L., Adams, C., \& Reynolds, L. (1999). Parent versus self-report: Contributions toward a diagnosis of adolescent psychopathology. Journal of Psychopathology, $21,349-363$.

Jankowski, M. K., Leitenberg, H., Henning, K., \& Coffey, P. (2002). Parental caring as a possible buffer against sexual revictimization in young adult survivors of child sexual abuse. Journal of Traumatic Stress, 15, 235-244.
Kendall-Tackett, K. A., Williams, L. M., \& Finkelhor, D. (1993). Impact of sexual abuse on children: A review and synthesis of recent empirical studies. Psychological Bulletin, 113, 164-180.

Ketring, S. A., \& Feinauer, L. L. (1999). Perpetrator-victim relationship: Long-term effects of sexual abuse for men and women. The American Journal of Family Therapy, 27, 109-120.

Kolko, D. J., Brown, E. J., \& Berliner, L. (2002). Children's perceptions of their abusive experience: Measurement and preliminary findings. Child Maltreatment, 7, $42-55$.

Leifer, M., \& Shapiro, J. P. (1995). Longitudinal study of the psychological effects of sexual abuse in African American girls in foster care and those who remain home. Journal of Child Sexual Abuse, 4, 27-44.

Lucenko, B. A., Gold, S. N., \& Cott, M. A. (2000). Relationship to perpetrator and posttraumatic symptomatology among sexual abuse survivors. Journal of Family Violence, 15, 169-179.

Manion, I., Firestone, P., Cloutier, P., Ligezinska, M., McIntyre, J., \& Ensom, R. (1998). Child extrafamilial sexual abuse: Predicting parent and child functioning. Child Abuse \& Neglect, 22, 1285-1304.

Mannarino, A. P., \& Cohen, J. A. (1996). Family-related variables and psychological symptom formation in sexually abused girls. Journal of Child Sexual Abuse, 5, 105-120.

Mannon, K., \& Leitschuh, G. (2002). Child sexual abuse: A review of definitions, instruction, and symptomology. North American Journal of Psychology, 4, 149-161.

Mansell, S., Sobsey, D., \& Moskal, R. (1998). Clinical findings among sexually abused children with and without developmental disabilities. Mental Retardation, 36, $12-22$.

McCourt, J., \& Peel, J. C. F. (1998). The effects of child sexual abuse on the protecting parent(s): Identifying a counseling response. Counseling Psychology Quarterly, 11, 283-300.

Mian, M., Marton, P., \& LeBaron, D. (1996). The effects of sexual abuse on 3- to 5-year-old girls. Child Abuse \& Neglect, 20, 731-745.

Nelson, W. M., Moser, A., Johnson, N. E., Graves, K., \& Hart, K. J. (1999). Behavioral characteristics of preadolescent girls from sexually abusive vs. dysfunctional families. Psychology: A Journal of Human Behavior, 36, 21-27.

Oates, R. K., Tebbutt, J., Swanston, H., Lynch, D. L., \& O’Toole, B. I. (1998). Prior childhood sexual abuse in mothers of sexually abused children. Child Abuse \& Neglect, 22, 1113-1118.

Paolucci, E. O., Genuis, M. L., \& Violato, C. (2001). A meta-analysis of the published research on the effects of child sexual abuse. Journal of Psychology, 1135, 17-37.

Ramchandani, P., \& Jones, D. P. H. (2003). Treating psychological symptoms in sexually abused children. British Journal of Psychiatry, 183, 484-490.

Ryan, K. D., Kilmer, R. P., Cause, A. M., Watanabe, H., \& Hoyt, D. R. (2000). Psy chological consequences of child maltreatment in homeless adolescents: Untangling the unique effects of maltreatment and family environment. Child Abuse \& Neglect, 24, 333-352.

Saywitz, K. J., Mannarino, A. P., Berliner, L., \& Cohen, J. (2000). Treatment for sexually abused children and adolescents. American Psychologist, 55, 1040-1049.

Smith, H., \& Israel, E. (1987). Sibling incest: A study of the dynamics of 25 cases. Child Abuse \& Neglect, 11, 101-108.

Spaccarelli, S., \& Kim, S. (1995). Resiliency criteria and factors associated with resilience in sexually abused girls. Child Abuse \& Neglect, 19(9), 1171-1182.

Steel, J. L., Wilson, G., Cross, H., \& Whipple, J. (1996). Mediating factors in the development of psychopathology in victims of childhood sexual abuse. Sexual Abuse: $A$ Journal of Research and Treatment, 8, 291-316.

Stern, A. E., Lynch, D. L., Oates, R. K., O’Toole, B. I., \& Cooney, G. (1995). Selfesteem, depression, behavior, and family functioning in sexually abused children. Journal of Child Psychology \& Psychiatry, 36, 1077-1089.

Tharinger, D. (1990). Impact of child sexual abuse on developing sexuality. Professional Psychology: Research and Practice, 21, 331-337.

U.S. Department of Health and Human Services, Administration on Children, Youth, and Families (2009). Child maltreatment 2007. Washington, DC: U.S. Government Printing Office 2003.

Valle, L. A., \& Silovsky, J. F. (2002). Attributions and adjustment following child sexual and physical abuse. Child Maltreatment, 7, 9-25.

Wolfe, D. A., Sas, L., \& Wekerle, C. (1994). Factors associated with the development of posttraumatic stress disorder among child victims of sexual abuse. Child Abuse \& Neglect, 18, 37-50.

Young, R. E., Bergandi, T. A., \& Titus, T. G. (1994). Comparison of the effects of sexual abuse on male and female latency-aged children. Journal of Interpersonal Violence, 9, 291-306. 